\title{
Genistein differentially modulates androgen-responsive gene expression and activates JNK in LNCaP cells
}

\author{
BATO LAZAREVIC ${ }^{1}$, STEINAR JOHAN KARLSEN ${ }^{1}$ and FAHRI SAATCIOGLU ${ }^{2}$ \\ ${ }^{1}$ Oslo Urological University Clinic, Aker University Hospital, University of Oslo, Trondheimsveien 235, 0514 Oslo; \\ ${ }^{2}$ Department of Molecular Biosciences, University of Oslo, PB 1041 Blindern, 0316 Oslo, Norway
}

Received October 26, 2007; Accepted December 27, 2007

\begin{abstract}
Genistein, the predominant isoflavone in soy, may be chemopreventive in prostate cancer $(\mathrm{CaP})$. It downregulates the prostate-specific antigen (PSA) and androgen receptor (AR) in androgen responsive cells. However, the extent of the down-regulation and whether genistein has a general effect on all androgen responsive genes (ARGs) are unclear. We investigated the ability of genistein to modulate ARG expression by the synthetic androgen R1881 in LNCaP cells. Given that there is important crosstalk between AR and mitogen activated protein kinase (MAPK) signaling, we also investigated whether genistein activates the MAPK end targets c-Jun N-terminal kinase (JNK) and c-Jun. Changes in ARG expression were determined by Western analysis and semi-quantitative RT-PCR. The activation of JNK and c-Jun was investigated by Western analysis and a solid phase kinase assay. The PSA protein and mRNA expression were both down-regulated by genistein. In contrast, KLK4 was upregulated at the mRNA, but down-regulated at the protein level. NKX3.1 mRNA levels did not change significantly, but protein levels were significantly down-regulated. STAMP2 mRNA levels slightly increased whereas the protein expression was down-regulated. The AR mRNA expression changed significantly only at high concentrations of genistein when it was down-regulated, whereas AR protein levels were decreased at low concentrations of genistein. The solid phase kinase assay indicated a transient activation of JNK by genistein, which was supported by Western analysis. Thus genistein differentially modulates ARG mRNA expression, but has an inhibitory role on the ARG protein levels. The activation of the JNK pathway which inhibits AR signaling may provide a mechanism for the overall inhibition of protein levels.
\end{abstract}

Correspondence to: Dr Fahri Saatcioglu, Department of Molecular Biosciences, University of Oslo, PB 1041 Blindern, 0316 Oslo, Norway

E-mail: fahri.saatcioglu@imbv.uio.no

Key words: prostate, LNCaP, genistein, androgen-responsive genes, mitogen activated protein kinases

\section{Introduction}

Soy is common in Asian diet, but rare in the western diet. There is a higher incidence and mortality of prostate cancer $(\mathrm{CaP})$ in western compared with Asian men. Certain epidemiological reports suggest that soy intake has a chemopreventive effect in CaP. However, other reports oppose this view $(1,2)$. Genistein is the predominant isoflavone in soy and it has multiple molecular effects of interest in this respect. Genistein is a phyto-estrogen as well as a tyrosine kinase inhibitor, and may influence a number of intracellular growth and signaling pathways (3). It induces $\mathrm{G} 2 / \mathrm{M}$ arrest, apoptosis and modulates $\mathrm{Bcl}-2$, p21 and p53 $(4,5)$. It modulates mitogen activated protein kinases (MAPK) ERK and p38 (6). Genistein inhibits angiogenesis, and inhibits steroid synthesis by inhibition of $3 \beta-$ and 17ß-hydroxysteroid dehydrogenase and $5 \alpha$-reductase (7-9). It also reverses hypermethylation and reactivates the mRNA expression of the retinoic acid receptor $\beta$ (RARß) and other silenced genes in prostate cancer cells (10).

Genistein down-regulates the prostate-specific antigen (PSA) and androgen receptor (AR) in the human prostate cell line LNCaP. The extent of the down-regulation has varied between publications, and different dosages of genistein have been used. Furthermore, both mRNA and protein expression has not always been investigated. The present study analysed the effect of genistein on the expression of five distinct androgen responsive genes (ARG): PSA, KLK4, NKX3.1, STAMP2 and AR in LNCaP cells at the mRNA and protein level. These genes were selected as they have conclusively been characterized as ARGs.

There are no previous studies reporting whether genistein modulates the MAPK end targets c-Jun N-terminal kinase (JNK) and c-Jun in LNCaP cells. This pathway may modulate both apoptosis and ARG protein expression in prostate cells.

\section{Materials and methods}

Cell culture. LNCaP cells were obtained from the American Type Culture Collection (Rockville, MD) and maintained as previously described (11). The passage numbers were between 10 and 20. For hormonal starvation before treatment, the cells were grown for $48 \mathrm{~h}$ in RPMI with $2 \%$ charcoal-treated (CT) fetal calf serum (FCS), followed by $24 \mathrm{~h}$ in RPMI with $0.5 \%$ CT FCS. 


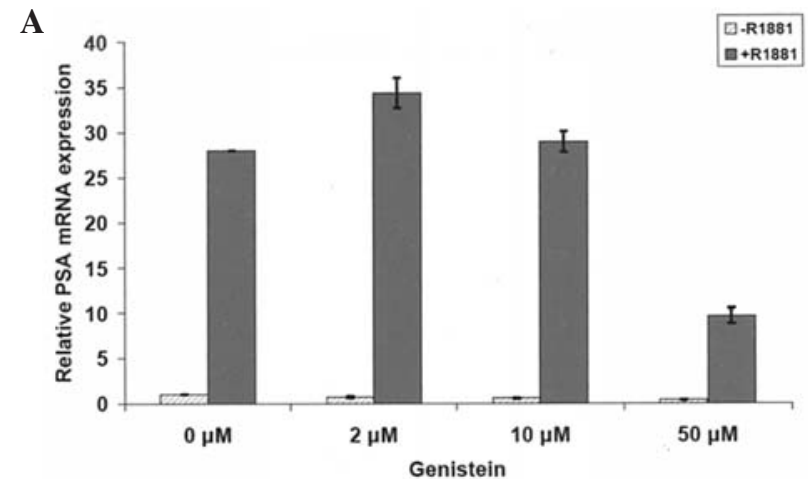

B

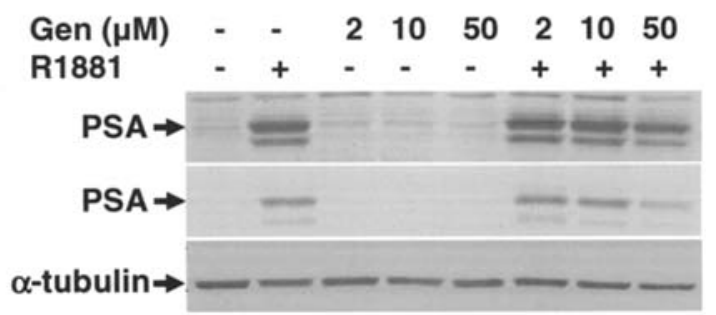

C

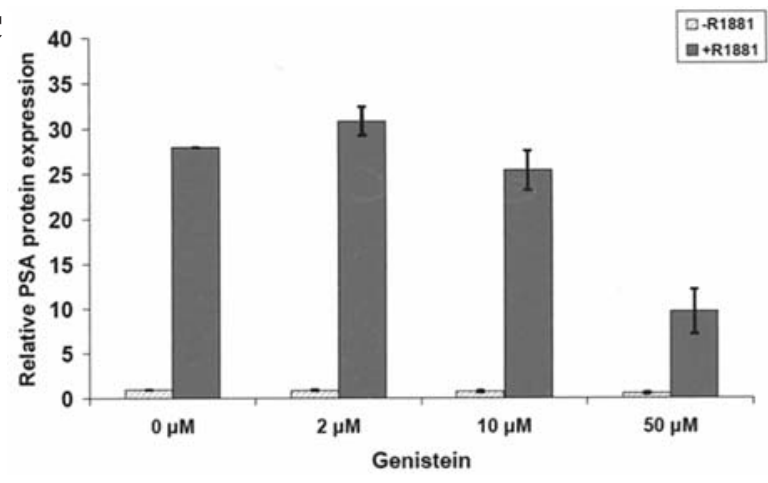

Figure 1. PSA gene expression. (A) Relative PSA mRNA expression levels in the LNCaP cells treated for $24 \mathrm{~h}$ with $0,2,10$ or $50 \mu \mathrm{M}$ genistein with or without R1881. (B) Western blots of PSA and $\alpha$-tubulin protein expression in the $\mathrm{LNCaP}$ cells treated for $24 \mathrm{~h}$ with $0,2,10$ or $50 \mu \mathrm{M}$ genistein with or without R1881. (C) Relative PSA protein expression levels in the LNCaP cells treated for $24 \mathrm{~h}$ with $0,2,10$ and $50 \mu \mathrm{M}$ genistein with or without R1881.

Chemicals. Thapsigargin (TG) and genistein were obtained from Sigma Aldrich and dissolved in dimethyl sulfoxide (DMSO). The synthetic androgen R1881 was obtained from Dupont-NEN and dissolved in EtOH.

Protein extraction and Western analysis. The LNCaP cells were treated with vehicle (DMSO/EtOH), genistein (2, 10 and $50 \mu \mathrm{M})$ in the presence or absence of R1881 $\left(10^{-8} \mathrm{M}\right)$, TG $(100 \mathrm{nM})$ or UV light $\left(2 \mathrm{~J} / \mathrm{cm}^{2}\right.$ for $\left.5 \mathrm{sec}\right)$ for the indicated time points. Whole cell protein extracts were prepared as previously described (11). Protein concentrations were determined by a Bio-Rad protein assay. Western analysis was performed by standard procedures using an enhanced chemiluminescence protocol (Amersham International). The primary antibodies used were PSA goat polyclonal antibody (Santa Cruz), totaland phospho-JNK rabbit polyclonal antibodies (New England Biolabs), $\alpha$-tubulin mouse monoclonal antibody (Sigma) and KLK4, NKX3.1, STAMP2 and AR polyclonal antibodies

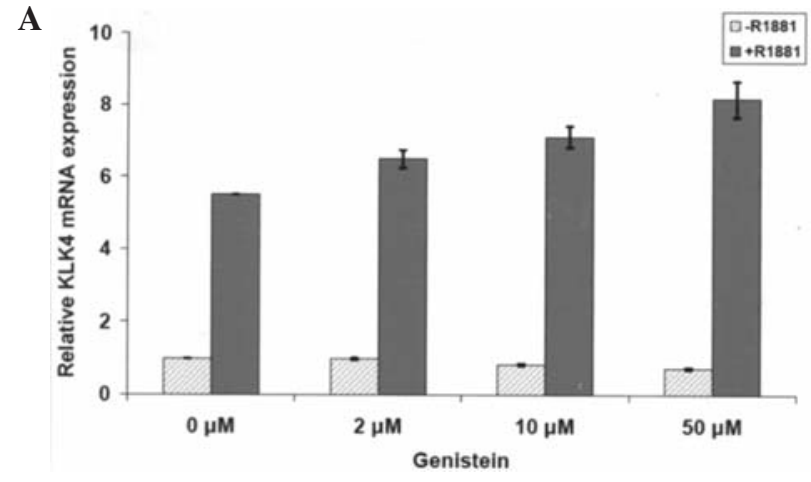

B

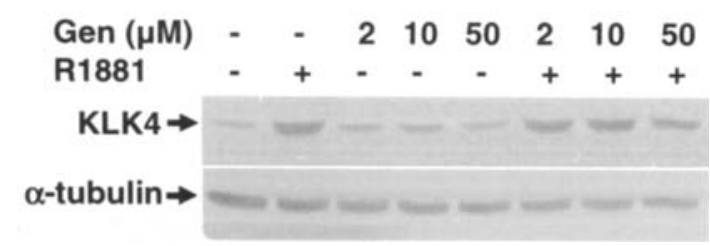

C

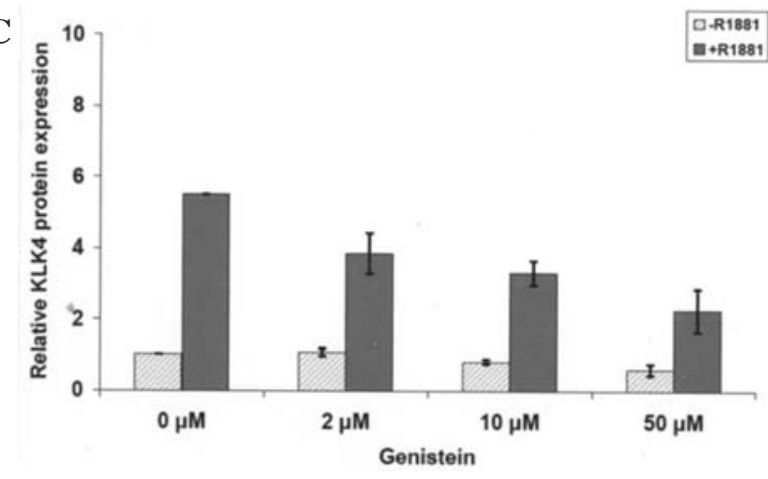

Figure 2. KLK4 gene expression. (A) Relative KLK4 mRNA expression levels in the LNCaP cells treated for $24 \mathrm{~h}$ with $0,2,10$ or $50 \mu \mathrm{M}$ genistein with or without R1881. (B) Western blots of KLK4 and $\alpha$-tubulin protein expression in the $\mathrm{LNCaP}$ cells treated for $24 \mathrm{~h}$ with $0,2,10$ or $50 \mu \mathrm{M}$ genistein with or without R1881. (C) Relative KLK4 protein expression levels in the $\mathrm{LNCaP}$ cells treated for $24 \mathrm{~h}$ with $0,2,10$ and $50 \mu \mathrm{M}$ genistein with or without R1881.

from immunized rabbits $(11,12)$. The mean values, corrected for $\alpha$-tubulin and the standard error of at least 3 individual experiments were calculated for each relative protein expression level.

The solid phase kinase assay. Whole cell protein extracts were prepared from cells treated for the indicated time points with vehicle (DMSO/EtOH), $100 \mathrm{nM}$ TG, $50 \mu \mathrm{M}$ genistein or $\mathrm{UV}$ light $\left(2 \mathrm{~J} / \mathrm{cm}^{2}\right.$ for $\left.5 \mathrm{sec}\right)$. A solid phase kinase assay was performed by using the fusion protein gluthatione S-transferase (GST) c-jun as previously described (13). The signals were detected and quantified by phospho-imager analysis.

mRNA extraction and cDNA synthesis. The LNCaP cells were treated with vehicle (DMSO/EtOH) or 2, 10 or $50 \mu \mathrm{M}$ genistein in the presence or absence of $10^{-8} \mathrm{M} \mathrm{R} 1881$ for $24 \mathrm{~h}$. Total mRNA was extracted with Trizol (Invitrogen) following the manufacturer's protocol. Total RNA (3-5 $\mu \mathrm{g}$ ) was reversetranscribed by random priming following the Superscript II system (Invitrogen). The mean values, corrected for ATP-6, 
A

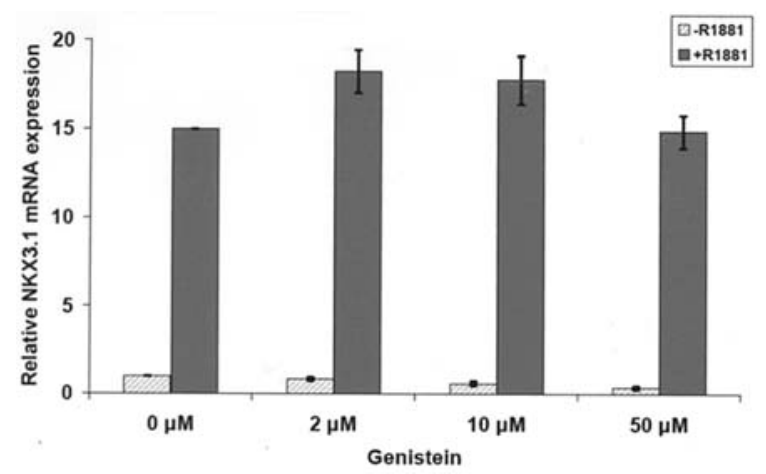

B

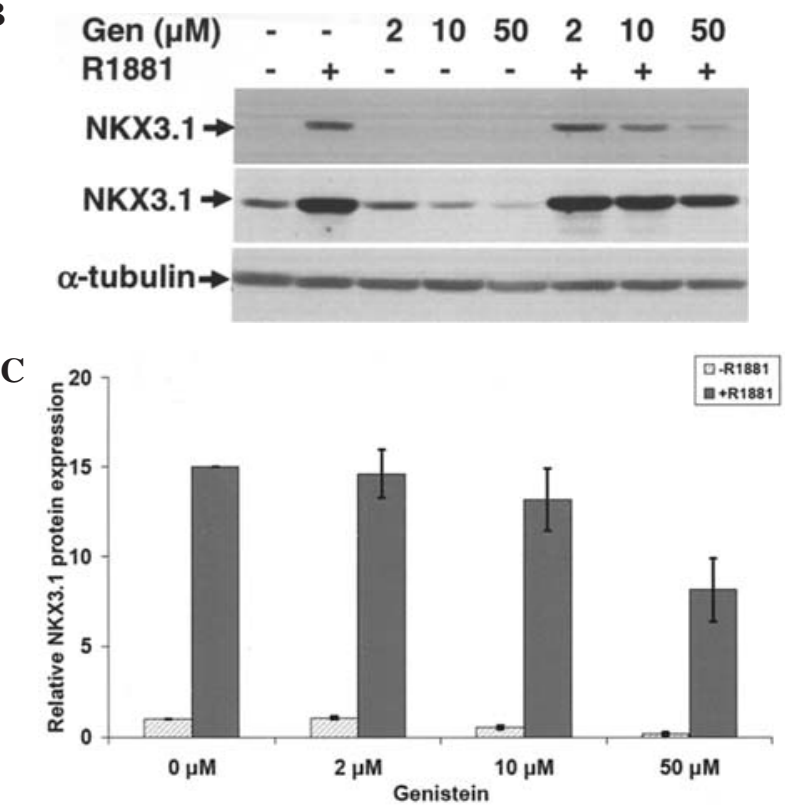

Figure 3. NKX3.1 gene expression. (A) Relative NKX3.1 mRNA expression levels in the LNCaP cells treated for $24 \mathrm{~h}$ with $0,2,10$ or $50 \mu \mathrm{M}$ genistein with or without R1881. (B) Western blots of NKX3.1 and $\alpha$-tubulin protein expression in the $\mathrm{LNCaP}$ cells treated for $24 \mathrm{~h}$ with $0,2,10$ or $50 \mu \mathrm{M}$ genistein with or without R1881. (C) Relative NKX3.1 protein expression levels in the $\mathrm{LNCaP}$ cells treated for $24 \mathrm{~h}$ with $0,2,10$ and $50 \mu \mathrm{M}$ genistein with or without R1881.

and the standard error of at least 3 independent experiments were calculated for each relative mRNA expression level.

Semi-quantitive RT-PCR. Amplification was performed in an $8 \mu 1$ light cycler DNA master SYBR-Green mix (Roche Diagnostics) containing 3-4 mM MgCl 2 , Taq start polymerase, forward and reverse primers and a $2 \mu 1 \mathrm{cDNA}$ template was used. All amplifications were run as triplicates with standard curves. After the final cycle melting point an analysis of all samples and control was performed within a range of $59-95^{\circ} \mathrm{C}$. The relative quantities were corrected for ATP-6. The primer pairs (5'-3') used were: CCCTGAGCACCCCTATCAAC and CACAACGCACCAGACACTCA for PSA; ATGGAAAAC GAATTGTTCTGCTC and CAGAATGCCTACCGTGCTG for KLK4; GGCCTGGGAGTCTCTTGACTCCACTAC and CATTTTCTGTGGTTTGGGCTCCACAT for NKX3.1; ATGACAGCAAAGCCAAGCAA and TTGACCACTGGA TGCTTTGC for STAMP2; GCCTTGCTCTCTAGCCTCAA and GGATGGCTGAAAAATCAAA for AR and CAGTGA
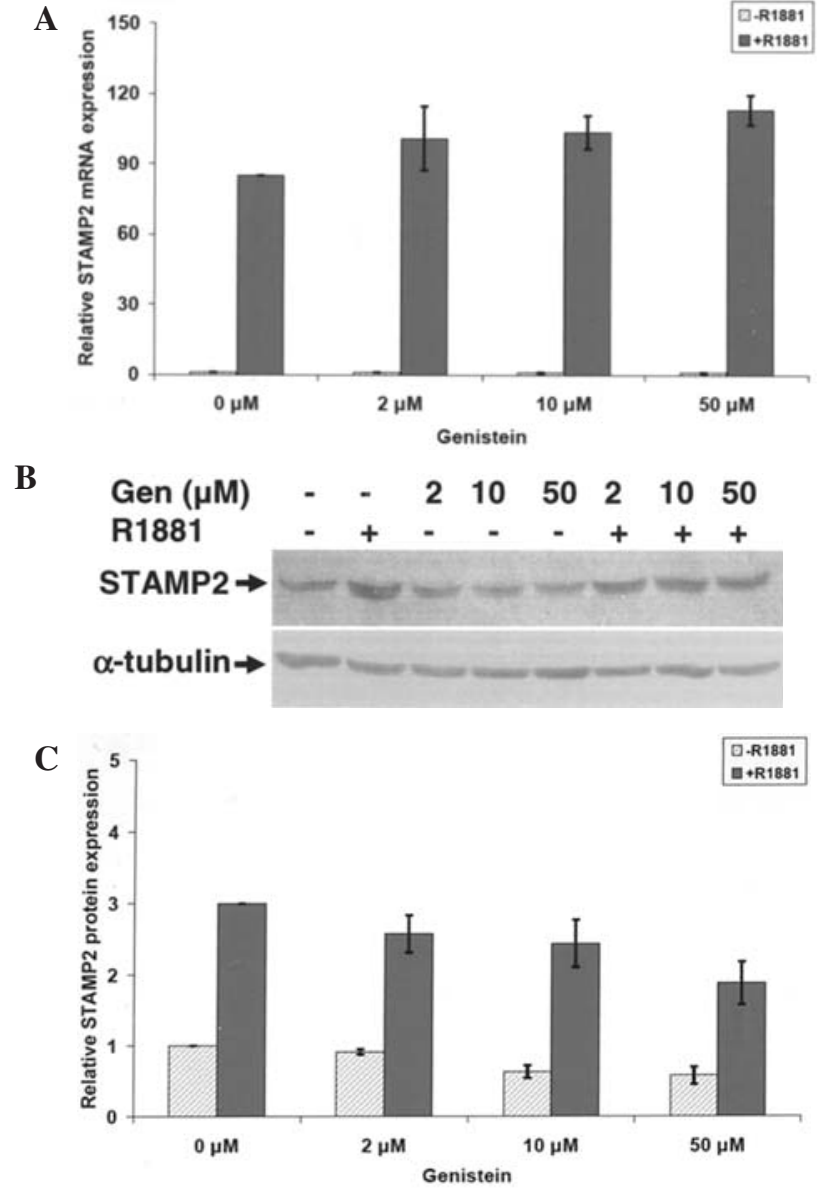

Figure 4. STAMP2 gene expression. (A) Relative STAMP2 mRNA expression levels in the LNCaP cells treated for $24 \mathrm{~h}$ with $0,2,10$ or $50 \mu \mathrm{M}$ genistein with or without R1881. (B) Western blots of STAMP2 and $\alpha$-tubulin protein expression in the LNCaP cells treated for $24 \mathrm{~h}$ with $0,2,10$ or $50 \mu \mathrm{M}$ genistein with or without R1881. (C) Relative STAMP2 protein expression levels in the LNCaP cells treated for $24 \mathrm{~h}$ with $0,2,10$ and $50 \mu \mathrm{M}$ genistein with or without R1881.

TTATAGGCTTTCGCTCTA and TACTCATTCAACCA ATAGCCCTG for ATP-6.

\section{Results}

Genistein differentially modulates the androgen-responsive gene expression. To assess the effect of genistein on ARG expression, the cells were treated with increasing amounts of genistein in the presence or absence of the synthetic androgen R1881. RNA and protein were isolated and used in either semi-quantitative RT-PCR or Western analysis for the different ARGs. As shown in Fig. 1, the PSA protein and mRNA expression was down-regulated by genistein starting at $10 \mu \mathrm{M}$ and reaching a maximum level of inhibition at $50 \mu \mathrm{M}$. As shown in Fig. 2, the KLK4 mRNA accumulation increased with genistein in a dose-dependent manner, but the KLK4 protein levels decreased. The mRNA levels of NKX3.1 did not change significantly, but the protein levels were significantly down-regulated in a dose-dependent manner, starting at $2 \mu \mathrm{M}$ genistein (Fig. 3). As with KLK4, STAMP2 mRNA levels increased in a dose-dependent manner whereas protein levels were down-regulated (Fig. 4). Under these conditions, the 

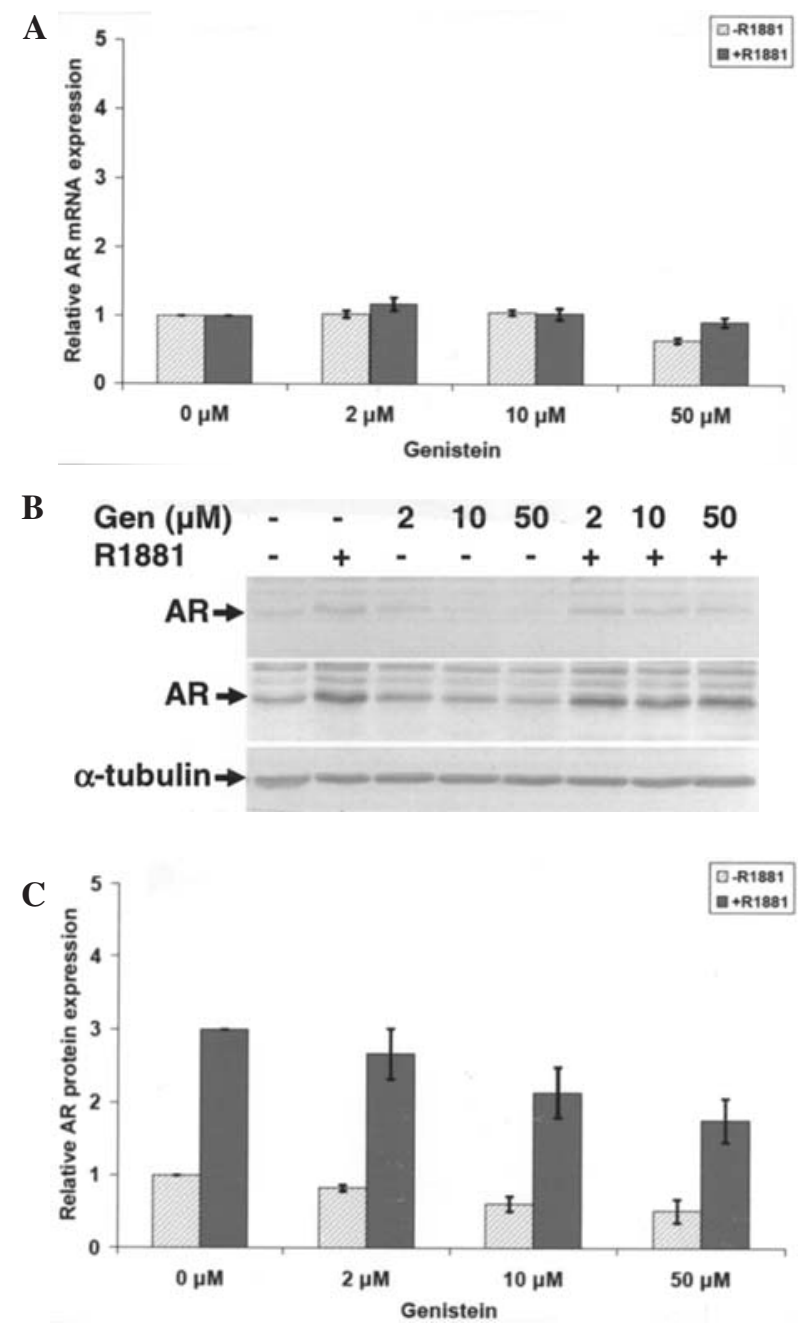

Figure 5. AR gene expression. (A) Relative AR mRNA expression levels in the LNCaP cells treated for $24 \mathrm{~h}$ with $0,2,10$ or $50 \mu \mathrm{M}$ genistein with or without R1881. (B) Western blots of AR and $\alpha$-tubulin protein expression in the $\mathrm{LNCaP}$ cells treated for $24 \mathrm{~h}$ with $0,2,10$ or $50 \mu \mathrm{M}$ genistein with or without R1881. (C) Relative AR protein expression levels in the LNCaP cells treated for $24 \mathrm{~h}$ with $0,2,10$ and $50 \mu \mathrm{M}$ genistein with or without R1881.

AR mRNA expression did not significantly change in response to genistein, whereas the AR protein levels decreased in a dose-dependent manner starting at $2 \mu \mathrm{M}$ (Fig. 5). The AR mRNA level was not induced by R1881, whereas the AR protein level increased three-fold, consistent with previous findings in the literature (14).

Genistein activates JNK. The JNK pathway has been implicated in its crosstalk with AR signaling (15). To assess the possible effects of genistein on JNK signaling, we performed Western analysis which indicated a weak transient phosphorylation of JNK in a time-dependent manner, starting at $1 \mathrm{~h}$ of treatment and peaking at $3 \mathrm{~h}$ in LNCaP cells (Fig. 6). The level of phosphorylation induced by genistein was similar to the known JNK activator TG after $36 \mathrm{~h}$ of treatment which declined to basal levels by $24 \mathrm{~h}$ (13). This transient activation of JNK was supported by the solid phase kinase assay (Fig. 7). Whole cell protein extracts made from LNCaP cells and treated with genistein for different time points were used with GST c-Jun as a substrate. As shown in Fig. 7, JNK activity
A
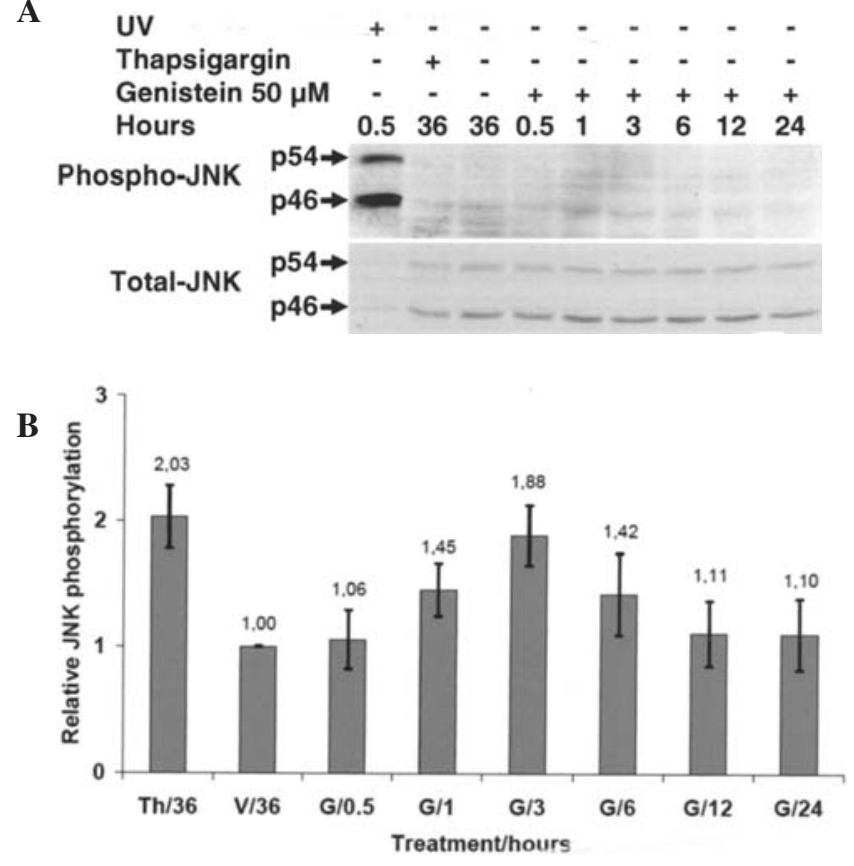

Figure 6. JNK phosphorylation. (A) Western blots of phospho- and total-JNK protein expression in the LNCaP cells treated with UV-radiation $\left(2 \mathrm{~J} / \mathrm{cm}^{2}\right.$ for $5 \mathrm{sec}$ and incubated for $30 \mathrm{~min}$ ), thapsigargin $100 \mathrm{nM}$ for $36 \mathrm{~h}$, vehicle for $36 \mathrm{~h}$ or genistein $50 \mu \mathrm{M}$ for $0.5-24 \mathrm{~h}$. (B) Relative JNK phosphorylation levels in the LNCaP cells treated with thapsigargin $100 \mathrm{nM}$ for $36 \mathrm{~h}(\mathrm{Th} / 36)$, vehicle for $36 \mathrm{~h}(\mathrm{~V} / 36)$ or genistein $50 \mu \mathrm{M}$ for $0.5-24 \mathrm{~h}(\mathrm{G} / 0.5-24)$. Mean values, corrected for total-JNK, and standard error of 4 individual experiments were calculated and p54 and p46 were included.
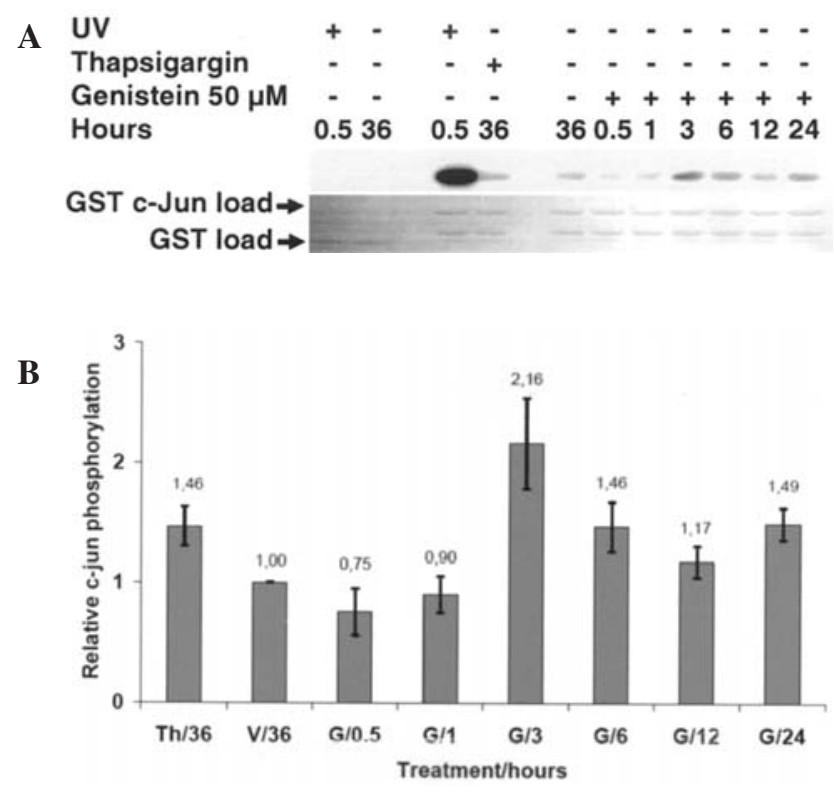

Figure 7. c-Jun phosphorylation. (A) Solid phase GST c-Jun kinase assay of the LNCaP whole cell extract. Cells were treated with UV-radiation $\left(2 \mathrm{~J} / \mathrm{cm}^{2}\right.$ for $5 \mathrm{sec}$ and incubated for $30 \mathrm{~min}$ ), thapsigargin $100 \mathrm{nM}$ for $36 \mathrm{~h}$, vehicle for $36 \mathrm{~h}$ or genistein $50 \mu \mathrm{M}$ for $0.5-24 \mathrm{~h} .{ }^{32} \mathrm{P}-\mathrm{ATP}$ was detected on a phosphorimager screen. GST control and c-jun fusion protein coupled to gluthatione agarose beads were prepared and detected on coomassie-stained SDS-PAGE gel. (B) Relative c-jun phosphorylation levels in LNCaP cells treated with thapsigargin $100 \mathrm{nM}$ for $36 \mathrm{~h}(\mathrm{Th} / 36)$, vehicle for $36 \mathrm{~h}(\mathrm{~V} / 36)$ or genistein $50 \mu \mathrm{M}$ for $0.5-24 \mathrm{~h}(\mathrm{G} / 0.5-24)$. Mean values and standard error of 4 individual experiments were calculated. 
peaked at $3 \mathrm{~h}$ of genistein treatment which was stronger than that obtained in response to TG. These data indicate that genistein has a significant, but transient, effect on the JNK signaling pathway.

\section{Discussion}

We performed a detailed expression analysis of ARGs in response to genistein in LNCaP cells. Our results show that whereas there are inhibitory effects of genistein on the ARG protein accumulation, the effect on mRNA levels did not always coincide with this, suggesting that there are different mechanisms through which genistein affects the AR signaling pathway. For example, whereas the PSA mRNA accumulation decreased in response to genistein, KLK4 mRNA levels increased. This suggests that genistein differentially affects transcriptional and post-transcriptional mechanisms in prostate cancer cells. It has previously been shown that genistein has distinct transcriptional and post-transcriptional effects $(3,10,16)$. Our data are consistent with these findings, but it is somewhat surprising that different ARGs respond differently to genistein at the mRNA level.

Genistein has been regarded as a general inhibitor of ARG expression. There is one report however, indicating that ARG expression does not modulate B2-microglobulin (B2M) and Selenoprotein P (SEPP1) mRNA accumulation, which are known as ARGs (17). Unfortunately, the effect of genistein on the protein accumulation level for these two ARGs has yet to be studied. Since our results indicate that genistein downregulated all tested ARG expression on the protein level, we would expect the same for B2M and SEPP1. Whether this is an effect on protein synthesis, stability or post-transcriptional effects on mRNA requires further investigation. For example, genistein may affect post-transcriptional processes, mRNA stability, transport to the cytosol or sequestration. It is also possible that genistein only modulates the ARG protein levels by affecting their stability. Additional experiments are needed to clarify these effects.

Another plausible mechanism of genistein action is through the activation of the JNK pathway. JNK phosphorylates and activates activating protein-1 (AP-1), composed of c-Jun and c-Fos oncoproteins, which then interferes with AR signaling $(18,19)$. More directly, JNK has been shown to phosphorylate AR and modulate its function (20). Thus, our finding that genistein directly activates JNK signaling suggests that its effects on ARG expression may be through this pathway.

Our conclusions are that genistein differentially modulates the ARG mRNA expression in LNCaP cells and inhibits ARG protein expression. Genistein activates the JNK pathway in LNCaP cells, which may in part explain the reduction of the ARG protein levels in response to genistein.

\section{References}

1. Jacobsen BK, Knutsen SF and Fraser GE: Does high soy milk intake reduce prostate cancer incidence? The Adventist Health Study (United States). Cancer Causes Control 9: 553-557, 1998.
2. Nomura AM, Hankin JH, Lee J and Stemmermann GN: Cohort study of tofu intake and prostate cancer: no apparent association. Cancer Epidemiol Biomarkers Prev 13: 2277-2279, 2004.

3. Akiyama T, Ishida J, Nakagawa S, et al: Genistein, a specific inhibitor of tyrosine-specific protein kinases. J Biol Chem 262: 5592-5595, 1987.

4. Davis JN, Singh B, Bhuiyan M and Sarkar FH: Genisteininduced up-regulation of p21WAF1, down-regulation of cyclin $\mathrm{B}$ and induction of apoptosis in prostate cancer cells. Nutr Cancer 32: 123-131, 1998.

5. Constantinou AI, Kamath N and Murley JS: Genistein inactivates bcl-2, delays the G2/M phase of the cell cycle, and induces apoptosis of human breast adenocarcinoma MCF-7 cells. Eur J Cancer 34: 1927-1934, 1998.

6. Frey RS and Singletary KW: Genistein activates p38 mitogenactivated protein kinase, inactivates ERK1/ERK2 and decreases Cdc25C expression in immortalized human mammary epithelial cells. J Nutr 133: 226-231, 2003.

7. Fotsis T, Pepper M, Adlercreutz H, et al: Genistein, a dietaryderived inhibitor of in vitro angiogenesis. Proc Natl Acad Sci USA 90: 2690-2694, 1993.

8. Le Bail JC, Champavier Y, Chulia AJ and Habrioux G: Effects of phyto-estrogens on aromatase, 3 beta and 17beta-hydroxysteroid dehydrogenase activities and human breast cancer cells. Life Sci 66: 1281-1291, 2000.

9. Evans BA, Griffiths K and Morton MS: Inhibition of 5 alphareductase in genital skin fibroblasts and prostate tissue by dietary lignans and isoflavonoids. J Endocrinol 147: 295-302, 1995.

10. Fang MZ, Chen D, Sun Y, Jin Z, Christman JK and Yang CS: Reversal of hypermethylation and reactivation of p16INK4a, RARbeta, and MGMT genes by genistein and other isoflavones from soy. Clin Cancer Res 11: 7033-7041, 2005.

11. Xi Z, Klokk TI, Korkmaz K, et al: Kallikrein 4 is a predominantly nuclear protein and is overexpressed in prostate cancer. Cancer Res 64: 2365-2370, 2004.

12. Korkmaz KS, Korkmaz CG, Ragnhildstveit E, Kizildag S, Pretlow TG and Saatcioglu F: Full-length cDNA sequence and genomic organization of human NKX3A - alternative forms and regulation by both androgens and estrogens. Gene 260: 25-36, 2000.

13. Engedal N, Korkmaz CG and Saatcioglu F: C-Jun N-terminal kinase is required for phorbol ester- and thapsigargin-induced apoptosis in the androgen responsive prostate cancer cell line LNCaP. Oncogene 21: 1017-1027, 2002.

14. van Laar JH, Berrevoets CA, Trapman J, Zegers ND and Brinkmann AO: Hormone-dependent androgen receptor phosphorylation is accompanied by receptor transformation in human lymph node carcinoma of the prostate cells. J Biol Chem 266: 3734-3738, 1991.

15. Fronsdal K, Engedal N, Slagsvold T and Saatcioglu F: CREB binding protein is a coactivator for the androgen receptor and mediates cross-talk with AP-1. J Biol Chem 273: 31853-31859, 1998.

16. Hong M, Lin MY, Huang JM, et al: Transcriptional regulation of the Grp78 promoter by endoplasmic reticulum stress: role of TFII-I and its tyrosine phosphorylation. J Biol Chem 280: 16821-16828, 2005.

17. Takahashi Y, Hursting SD, Perkins SN, Wang TC and Wang TT: Genistein affects androgen-responsive genes through both androgen- and estrogen-induced signaling pathways. Mol Carcinog 45: 18-25, 2006.

18. Angel P and Karin M: The role of Jun, Fos and the AP-1 complex in cell proliferation and transformation. Biochim Biophys Acta 1072: 129-157, 1991

19. Sato N, Sadar MD, Bruchovsky N, et al: Androgenic induction of prostate-specific antigen gene is repressed by protein-protein interaction between the androgen receptor and AP-1/c-Jun in the human prostate cancer cell line LNCaP. J Biol Chem 272: 17485-17494, 1997.

20. Gioeli D, Black BE, Gordon V, et al: Stress kinase signaling regulates androgen receptor phosphorylation, transcription, and localization. Mol Endocrinol 20: 503-515, 2006. 